OPEN ACCESS

Edited by: Filippo Tempia, Università degli Studi di Torino, Italy

Reviewed by: Andres Barria University of Washington, United States Marco Fuenzalida, Universidad de Valparaíso, Chile

*Correspondence: Patricia C. Salinas p.salinas@ucl.ac.uk

Received: 22 June 2018 Accepted: 10 October 2018 Published: 30 October 2018

Citation: Buechler $J$ and Salinas PC (2018) Deficient Wnt Signaling and Synaptic Vulnerability in Alzheimer's

Disease: Emerging Roles for the LRP6 Receptor.

Front. Synaptic Neurosci. 10:38 doi: 10.3389/fnsyn.2018.00038

\section{Deficient Wnt Signaling and Synaptic Vulnerability in Alzheimer's Disease: Emerging Roles for the LRP6 Receptor}

\author{
Johanna Buechler and Patricia C. Salinas* \\ Department of Cell and Developmental Biology, University College London, London, United Kingdom
}

Synapse dysfunction and loss represent critical early events in the pathophysiology of Alzheimer's disease (AD). While extensive research has elucidated the direct synaptotoxic effects of Amyloid- $\beta(A \beta)$ oligomers, less is known about how signaling pathways at the synapse are affected by $A \beta$. A better understanding of the cellular and molecular mechanisms underlying synaptic vulnerability in $A D$ is key to illuminating the determinants of $A D$ susceptibility and will unveil novel therapeutic avenues. Canonical Wnt signaling through the Wnt co-receptor LRP6 has a critical role in maintaining the structural and functional integrity of synaptic connections in the adult brain. Accumulating evidence suggests that deficient Wnt signaling may contribute to AD pathology. In particular, LRP6 deficiency compromises synaptic function and stability, and contributes to AB production and plaque formation. Here, we review the role of Wnt signaling for synaptic maintenance in the adult brain and the contribution of aberrant Wnt signaling to synaptic degeneration in $A D$. We place a focus on emerging evidence implicating the LRP6 receptor as an important modulator of AD risk and pathology.

Keywords: synaptic degeneration, Alzheimer's disease, amyloid-beta, Wnt signaling, LRP6

\section{INTRODUCTION}

Neurodegenerative diseases are characterized by progressive deterioration of nerve cell function and widespread neuronal death. Among them, Alzheimer's disease (AD) represents the most common form of dementia, associated with debilitating mental and cognitive decline (Alzheimer's Association, 2016). Due to changing demographics and increasing life expectancies, AD is rapidly rising in prevalence and its economic and social impact on our societies is predicted to soar in the coming decades (Hebert et al., 2001; Prince et al., 2013; Alzheimer's Association, 2016). No disease-modifying treatments are available for AD. Therefore, there is an urgent need to develop effective therapeutic approaches to halt or slow disease progression. Intense research over the past decades has begun to reveal the complex mechanistic underpinnings of $\mathrm{AD}$ involving genetic risk, age-related cellular vulnerability and lifestyle factors. However, the molecular and cellular determinants of $\mathrm{AD}$ susceptibility or resilience and the key mechanisms that drive disease progression remain poorly understood.

$\mathrm{AD}$ presents a variety of pathological hallmarks including extracellular aggregations of amyloid- $\beta(A \beta)$ protein, intracellular neurofibrillary tangles of tau protein and neuroinflammation mediated by glial cells. However, the best correlate of cognitive decline in AD patients is synapse 
loss, which occurs during early disease stages and precedes neuronal death (DeKosky and Scheff, 1990; Terry et al., 1991; Scheff et al., 1993; DeKosky et al., 1996; Selkoe, 2002). Synaptic impairments manifest early also in transgenic mouse models of AD (Knobloch and Mansuy, 2008; Hong et al., 2016a; Viana da Silva et al., 2016). Therefore, synaptic dysfunction and loss are key early events in the pathogenesis of AD. Protection of synapses and/or restoration of synaptic function is an attractive therapeutic strategy, as it may offer a chance of reversing or halting cognitive decline before the onset of large-scale and irreversible neuronal death. Understanding the molecular and cellular mechanisms that trigger synapse vulnerability in $\mathrm{AD}$ is critical for therapeutic development.

Research into the causes of synaptic degeneration in $\mathrm{AD}$ has focused on the role of soluble oligomers of $A \beta$ protein. $A \beta$ peptides, derived through enzymatic cleavage of the amyloid precursor protein (APP), self-aggregate into oligomers which are widely regarded as the principal pathogenic agents in $\mathrm{AD}$ (McLean et al., 1999; Näslund et al., 2000; Esparza et al., 2013). Indeed, $A \beta$ oligomers exert a multitude of synaptotoxic effects (Palop and Mucke, 2010; Ferreira and Klein, 2011; Tu et al., 2014; Forner et al., 2017). Oligomeric A $\beta$ accumulates at synaptic sites, impairs synaptic transmission and plasticity, compromises the structural integrity of dendritic spines and triggers spine and synapse elimination (Walsh et al., 2002; Hsieh et al., 2006; Shankar et al., 2008; Koffie et al., 2009; Wei et al., 2010; Pickett et al., 2016).

Several studies suggest that $A \beta$ also initiates a variety of downstream events, which lead to the deregulation of key cellular pathways that control synaptic function and integrity. For example, $A \beta$ downregulates the receptor tyrosine kinase EphB2, which is important for NMDA receptor trafficking to synaptic sites (Cissé et al., 2011; Miyamoto et al., 2016). A $\beta$ also induces the aberrant re-activation of developmental mechanisms of synapse elimination, driven by complement proteins and microglia (Schafer and Stevens, 2010; Stephan et al., 2012; Hong et al., 2016b). Another downstream target of $A \beta$ is the Wnt pathway, a key signaling cascade at the synapse. Growing evidence suggests that deficient Wnt signaling contributes to synaptic dysfunction and loss during $\mathrm{AD}$ pathogenesis. Multiple $A \beta$-targeting treatments have failed to produce appreciable cognitive benefits in $\mathrm{AD}$ clinical trials in recent years (Holmes et al., 2008; Doody et al., 2013, 2014; Vellas et al., 2013; Salloway et al., 2014). It is therefore critical to understand the downstream cellular responses to $A \beta$ to identify new therapeutic targets. Here, we will summarize emerging evidence that deficient Wnt signaling could contribute to synaptic degeneration in $\mathrm{AD}$, focusing on the key role of the Wnt co-receptor LRP6.

\section{Wnt SIGNALING AND SYNAPSE HEALTH IN THE ADULT BRAIN}

Wnt proteins are a family of highly conserved secreted lipoproteins that activate several intracellular signaling pathways and control key aspects of development and tissue homeostasis in all metazoans (Gordon and Nusse, 2006; MacDonald et al., 2009;
Nusse and Clevers, 2017). Wnt signaling plays a vital role in the nervous system, from embryogenesis to higher brain function in the adult.

The most extensively studied signaling cascade activated by Wnts is the canonical or $\beta$-catenin pathway, which regulates the stability of the transcriptional co-activator $\beta$-catenin, thereby controlling the expression of Wnt target genes (Figure 1). Wnt ligands bind to Frizzled (Fz) receptors and LRP5/6 co-receptors resulting in the formation of a ternary complex of Wnt, Fz and LRP5/6 at the cell surface (MacDonald et al., 2009; Clevers and Nusse, 2012; MacDonald and He, 2012; Nusse and Clevers, 2017). The downstream signaling cascade from this receptor complex leads to recruitment of the scaffold protein Dishevelled (Dvl) to the plasma membrane and inhibition of GSK3 $\beta$. $\beta$-catenin can then accumulate in the cytoplasm and translocate to the nucleus, where it regulates the expression of Wnt target genes in association with TCF/LEF transcription factors (Figure 1A; Cong et al., 2003; Valenta et al., 2012; Schuijers et al., 2014). When the pathway is inactive, cytosolic $\beta$-catenin is degraded by a macromolecular destruction complex composed of the scaffold protein Axin, the tumor suppressor protein APC and the two constitutively active serine-threonine kinases CK1 and GSK3ß (Figure 1B).

The Wnt signaling pathway is regulated by a range of secreted endogenous antagonists, that either modify or sequester Wnt ligands or modulate Wnt-receptor interactions at the plasma membrane (Cruciat and Niehrs, 2013). The best characterized Wnt antagonists are the Dickkopf (Dkk) proteins, a small evolutionarily conserved family of secreted glycoproteins with four members in vertebrates, Dkk1-4, (Niehrs, 2006; Cruciat and Niehrs, 2013). Dkk1 in particular is well characterized as a major endogenous Wnt antagonist. Dkk1 inhibits Wnt signaling by binding to the Wnt co-receptor LRP6, preventing the formation of the Wnt-Fz-LRP6 complex and the activation of the Wnt cascade (Figure 1B; Bafico et al., 2001; Mao et al., 2001; Semënov et al., 2001). Thus, increased levels of Dkk1 would decrease the availability of the LRP6 receptor for Wnt ligands.

During postnatal brain development, Wnts play an important role for synapse assembly in the CNS (reviewed in Ille and Sommer, 2005; Salinas and Zou, 2008; Budnik and Salinas, 2011; Park and Shen, 2012; Salinas, 2012; Stamatakou and Salinas, 2014). Many Wnt signaling components are also expressed in the adult mammalian nervous system (Shimogori et al., 2004; Wayman et al., 2006; De Ferrari et al., 2007; Gogolla et al., 2009; Sahores et al., 2010; Seib et al., 2013; Zhang et al., 2014). Accumulating evidence indicates a significant contribution of Wnt signaling to synapse physiology and stability in the adult brain.

Wnt signaling is important for synaptic transmission at mature synapses. Blockade of endogenous Wnts through sFRP Wnt antagonists, which sequester Wnt ligands in the extracellular space, reduces glutamatergic neurotransmission in cultured neurons (Varela-Nallar et al., 2010; Cerpa et al., 2011; Ciani et al., 2015). In contrast, application of exogenous Wnts acutely enhances excitatory synaptic transmission in mature hippocampal neurons (Beaumont et al., 2007; Cerpa et al., 


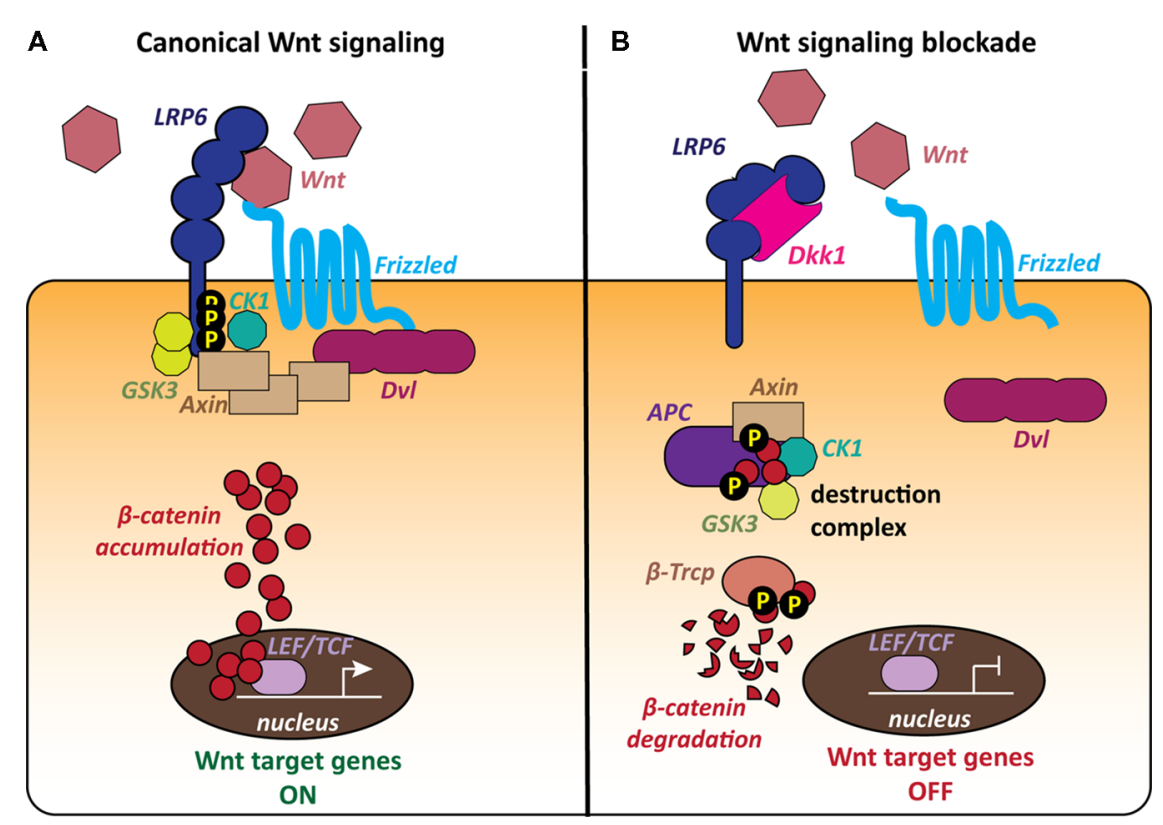

FIGURE 1 | The canonical Wnt pathway and the role of the LRP6 receptor. The LRP6 receptor occupies a unique position within the canonical Wnt pathway as it is involved in both activation and blockade of the cascade. (A) The canonical Wnt cascade is activated by binding of secreted Wnt molecules to the Frizzled (Fz) receptor and LRP6 co-receptor at the cell surface. The formation of this complex leads to the recruitment of the scaffold protein Dishevelled (Dvl) and

phosphorylation of the LRP6 C-tail by the kinases GSK3 and CK1. Cytoplasmic $\beta$-catenin accumulates and then translocates to the nucleus and activates Wnt target genes. (B) The secreted Wnt antagonist Dickkopf 1 (Dkk1) blocks Wnt signaling by binding to the LRP6 receptor, thereby preventing the formation of the Wnt-Fz-LRP6 complex. The cytoplasmic destruction complex containing Axin, APC, GSK3 and CK1 phosphorylates $\beta$-catenin, targeting it for proteasomal degradation. Wnt target genes remain repressed.

2008; Avila et al., 2010; Varela-Nallar et al., 2010; Ciani et al., 2011, 2015). In vivo, genetic deficiency in Wnt7a and Dvl1 results in reduced synaptic vesicle numbers and decreased transmitter release (Ahmad-Annuar et al., 2006; Ciani et al., 2015). Therefore, Wnts are required in mature neuronal circuits for synaptic function.

Wnt signaling also contributes to the structural stability of established synaptic connections (reviewed in Dickins and Salinas, 2013). Short-term blockade of canonical Wnt signaling through the secreted Wnt antagonist Dkk1 induces the disassembly of excitatory synapses in mature hippocampal neurons (Purro et al., 2012). Dkk1 decreases the number and size of pre- and postsynaptic protein clusters through the rapid dispersal of synaptic components, without affecting cell viability (Purro et al., 2012). Electron microscopy analyses show that remaining synapses have smaller active zones and postsynaptic densities, suggesting that Wnt blockade induces coordinated shrinkage and elimination of pre- and postsynaptic sites (Purro et al., 2012). In vivo suppression of Wnt signaling through inducible expression of Dkk1 in the adult brain of transgenic mice recapitulates these effects by eliciting synapse degeneration (Galli et al., 2014; Marzo et al., 2016). In the striatum, Wnt inhibition by Dkk1 leads to the loss of excitatory cortico-striatal as well as dopaminergic synapses and reduced neurotransmission at remaining synapses (Galli et al., 2014). In the hippocampus, Dkk1 triggers excitatory synapse loss, accompanied by defects in synaptic plasticity (blocked LTP and enhanced LTD) and memory function (Marzo et al., 2016). Synaptic degeneration occurs in the absence of cell death, indicating that Dkk1-mediated Wnt blockade directly compromises synapse stability and integrity (Galli et al., 2014; Marzo et al., 2016). Collectively, these findings demonstrate that endogenous Wnt signaling is required for synapse stability in the mature brain.

The physiological relevance of Wnt-regulated synaptic integrity is underscored by the implication of Wnt signaling in memory formation (reviewed in Oliva et al., 2013). Several studies have shown that blockade of Wnt signaling in the adult brain interferes with memory function. During fear memory consolidation in the amygdala, a transient increase in both $\beta$-catenin and Wnt target gene expression is observed (Maguschak and Ressler, 2011). In contrast, local injection of the Wnt antagonist Dkk1 disrupts memory consolidation (Maguschak and Ressler, 2011). A separate study similarly showed that administration of Wnt3a antibody or Wnt antagonists sFRP1 or Dkk1 block fear memory acquisition and consolidation, whereas infusion of exogenous Wnt3a enhances memory formation (Xu et al., 2015). Post-training infusion of Dkk1 also interferes with memory consolidation in a hippocampus-dependent object recognition task (Fortress et al., 2013). In vivo induction of Dkk1 expression in the adult hippocampus leads to memory deficits in a range of paradigms, including spatial navigation and fear memory (Marzo et al., 2016). Together, these studies show that Wnt signaling is 
required for synaptic changes underlying memory formation and consolidation.

\section{ABERRANT Wnt SIGNALING CONTRIBUTES TO SYNAPTIC VULNERABILITY IN AD}

Accumulating evidence suggests that aberrant Wnt signaling plays a role in the pathogenesis of $\mathrm{AD}$ (reviewed in De Ferrari et al., 2014; Inestrosa and Varela-Nallar, 2014; Purro et al., 2014; Libro et al., 2016; García-Velázquez and Arias, 2017). Multiple findings indicate that Wnt signaling becomes deregulated in the context of AD. In brains of familial AD patients, active GSK3 $\beta$ accumulates, whereas $\beta$-catenin levels are reduced (Zhang et al., 1998; Pei et al., 1999; Kawamura et al., 2001). Dkk1 expression is increased in brains from $\mathrm{AD}$ patients and transgenic $\mathrm{AD}$ mouse models (Caricasole et al., 2004; Rosi et al., 2010). Dkk3, which is closely related to Dkk1, is also elevated in plasma and cerebrospinal fluid of AD patients (Zenzmaier et al., 2009). Moreover, exposure of hippocampal neurons to $A \beta$ leads to inhibition of Wnt signaling (De Ferrari et al., 2003; Alvarez et al., 2004). Consistent with these findings, $A ß$ rapidly increases the levels of the endogenous Wnt antagonist Dkk1 (Purro et al., 2012). Together, these results indicate a deficiency of Wnt signaling in the context of $\mathrm{AD}$.

How does perturbation of Wnt signaling influence $A D$ pathogenesis? Suppression of Wnt signaling by $A B$ could decrease Wnt-dependent synaptic stability during the early stages of $\mathrm{AD}$. Consistent with this hypothesis, short-term exposure of hippocampal neurons to oligomeric $\mathrm{A} \beta$ induces Dkk1 expression and triggers synapse loss (Purro et al., 2012; Sellers et al., 2018). Importantly, neutralizing antibodies against Dkk1 protect synapses from $A \beta$ toxicity (Purro et al., 2012). Interestingly, a recent study suggests that Dkk1 may signal through its receptor Kremen1 to mediate $A \beta$ synaptotoxicity (Ross et al., 2018). In summary, these findings strongly suggest that Dkk1 is involved in $\mathrm{A}$-mediated synapse loss.

To mimic the effect of $A \beta$ in vivo, a transgenic mouse model that inducibly expresses Dkk1 was generated. Inhibition of endogenous Wnt signaling by Dkk1 in vivo triggers synapse loss in the striatum and hippocampus (Galli et al., 2014; Marzo et al., 2016). Hippocampal Dkk1 expression reduces synaptic transmission, impairs LTP and enhances LTD, and these synaptic defects are accompanied by memory deficits (Marzo et al., 2016). Thus, inducible Dkk1 expression in the adult brain mimics various aspects of $A \beta$-induced synaptic degeneration. These findings support the view that suppression of Wnt signaling downstream of $A \beta$ promotes synaptic destabilization and may contribute to cognitive decline.

\section{THE LRP6 RECEPTOR AS A KEY EMERGING LINK BETWEEN Wnt SIGNALING, SYNAPSE HEALTH AND AD}

Activation of the canonical Wnt pathway requires the cooperation of $\mathrm{Wnt} / \mathrm{Fz}$ with the single-pass transmembrane co-receptors LRP5/6, which belong to the extended low-density lipoprotein receptor (LDLR) family (He et al., 2004; MacDonald and He, 2012). LRP5 and LRP6 are highly homologous and display largely overlapping expression patterns, however LRP6 plays a more influential role and is the best characterized Wnt co-receptor (MacDonald et al., 2011). LRP6 is key for Wnt signal transduction, which relies on the phosphorylation of the LRP6 intracellular domain following Wnt binding to this co-receptor (He et al., 2004; MacDonald and He, 2012). LRP6 is also the main receptor for the Dkk family of Wnt secreted antagonists, most notably Dkk1 (Bafico et al., 2001; Mao et al., 2001; Semënov et al., 2001). Dkk1 disrupts LRP6 function as a Wnt co-receptor. The LRP6 receptor therefore occupies a unique position within the Wnt pathway (Figure 1).

\section{The Role of LRP6 in Embryogenesis and Synapse Formation}

Constitutive knockout of LRP6 is lethal, as $\mathrm{LRPG}^{-/-}$mice die at birth due to early patterning defects (Pinson et al., 2000). Loss of function of LRP6 causes severe defects specifically in the nervous system, including reduced production of granule cells in the hippocampus, deficiency in thalamic development and impaired neuronal proliferation in the neocortex (Zhou et al., 2004a,b, 2006). Therefore, LRP6 plays a critical role during early development, consistent with its role as a key Wnt receptor in the canonical Wnt pathway.

LRP6 is also important during synapse formation in the developing nervous system. Knockdown of LRP6 in young hippocampal neurons leads to a decrease in the number of excitatory synapses and impairs spine morphogenesis, without affecting inhibitory synapses (Sharma et al., 2013). Similarly, in vivo loss of function of LRP6 in developing cortical neurons compromises dendritic spine development, accompanied by a functional impairment of excitatory postsynaptic currents (Sharma et al., 2013). LRP6 phosphorylation at residue S1490, which is a key step during Wnt signal transduction, is required for LRP6-mediated synaptogenesis (Sharma et al., 2013). Thus, LRP6 has a key role in Wnt-mediated synapse formation and is required for excitatory synapse formation during postnatal development.

\section{LRP6 and Synapse Integrity in the Adult and Aging Brain}

The role of LRP6 in the mature brain was investigated in a conditional knockout (cKO) model, based on CaMKII-Credriven deletion of LRP6 in principal forebrain neurons (Liu et al., 2014). LRP6 cKO impairs Wnt signaling and causes synapse dysfunction and loss in an age-dependent manner. Spine density, synaptic protein levels, synaptic plasticity and memory function are normal in young adult $\mathrm{cKO}$ mice at 6 months (Liu et al., 2014). However, LRP6 cKO mice at 18-22 months exhibit spine loss in hippocampal and cortical neurons, impaired LTP maintenance and memory deficits in fear conditioning tests (Liu et al., 2014). Reduced cell viability 


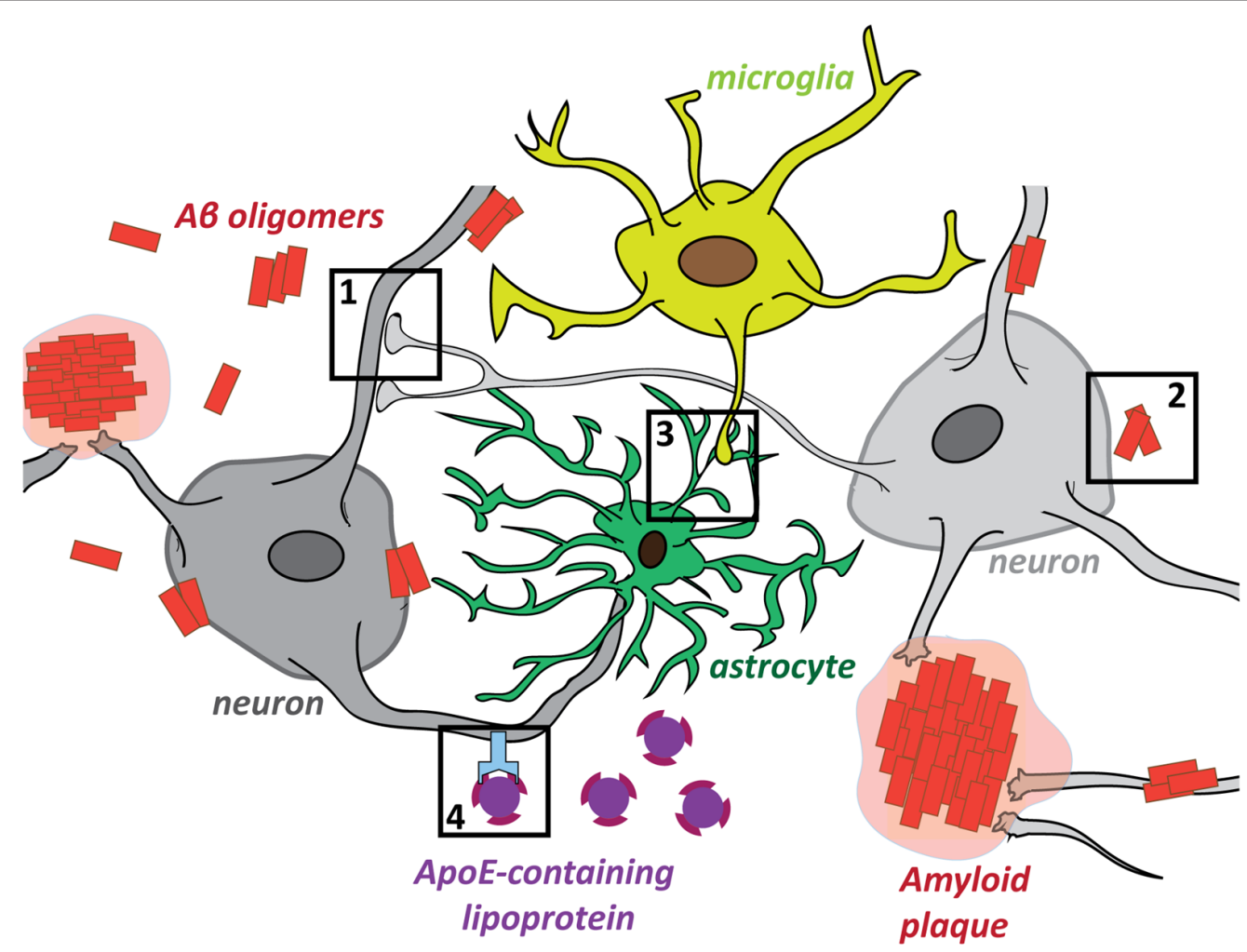

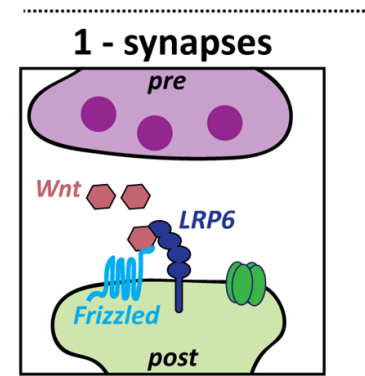

LRP6 is present at synapses. Deficiency in LRP6-mediated Wnt signaling compromises synaptic plasticity and stability during ageing.

\section{2 - Amyloid-6}

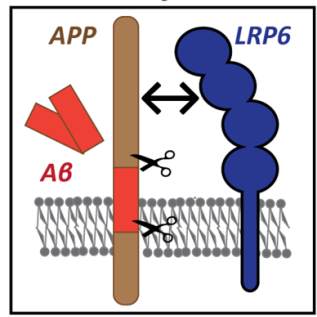

LRP6 interacts with APP.

LRP6 deficiency promotes $A B$ production and plaque deposition.

\section{3 - glia cells}

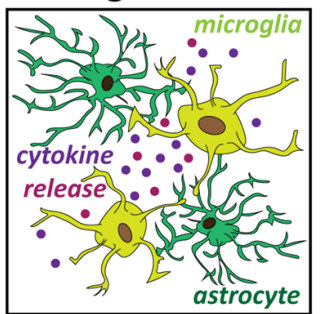

Neuronal LRP6 deficiency induces neuroinflammation and release of pro-

inflammatory cytokines.

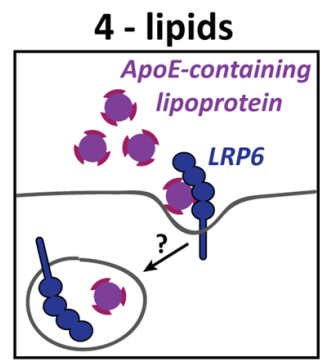

LRP6 is involved in lipid metabolism and could bind and internalize ApoEcontaining lipoproteins.

FIGURE 2 | Potential roles for the LRP6 receptor in several key pathogenic processes in Alzheimer's disease (AD). Several hallmarks of AD pathology have been identified and LRP6 dysfunction contributes to these pathogenic processes in multiple different ways: (1) Deficiency in LRP6-mediated Wnt signaling increases synaptic vulnerability, which could promote synaptic dysfunction and loss in AD; (2) LRP6 regulates amyloid precursor protein (APP) processing and LRP6 loss of function increases amyloid- $\beta$ (A $\beta$ ) generation and plaque formation; (3) Neuroinflammatory processes also contribute to AD pathology. Neuronal LRP6 deficiency has a secondary impact on microglia and astrocytes, promoting neuroinflammation and secretion of pro-inflammatory molecules; (4) Lipid metabolism is deregulated in $A D$ and Apolipoprotein E (ApoE) is a major genetic risk factor for AD. LRP6 could participate in cholesterol transport and may be involved in the internalization of ApoE-containing lipoprotein particles.

may contribute to these effects (Liu et al., 2014). Thus, neuronal LRP6 deficiency leads to synaptic dysfunction and loss, accompanied by cognitive impairment, specifically in the aging brain (Figure 2, panel 1).

\section{LRP6 and Links to AD}

Several studies suggest a link between LRP6 and AD. Through genome-wide linkage analyses, a broad susceptibility locus for late-onset $\mathrm{AD}$ was identified on chromosome 12, which includes the region encoding LRP6 (Pericak-Vance et al., 1997; Rogaeva et al., 1998; Kehoe et al., 1999; Scott et al., 2000; Mayeux et al., 2002; Myers et al., 2002; D'Introno et al., 2006; Lee et al., 2008). Follow-up studies associated two LRP6 single-nucleotide polymorphisms (SNPs) and one alternative splice variant of LRP6 with an increased risk of late-onset AD (De Ferrari et al., 2007; Alarcón et al., 2013). These observations establish 
a genetic link between late-onset AD and LRP6. Both the LRP6 $14 \mathrm{e}-\mathrm{Val}$ variant and the LRP $6 \Delta 3$ splice isoform, which skips exon 3 , are associated with reduced activation of $\mathrm{Wnt} / \beta$-catenin signaling in HEK293T cells (De Ferrari et al., 2007; Alarcón et al., 2013).

In human $\mathrm{AD}$ brains, LRP6 mRNA and protein levels are significantly downregulated compared to age-matched controls (Liu et al., 2014). Concomitant reduction in canonical Wnt signaling suggests that LRP6-mediated Wnt signaling is compromised in AD (Liu et al., 2014). LRP6 deficiency promotes $\mathrm{AD}$ pathology as the levels of soluble $\mathrm{A} \beta_{40 / 42}$ and amyloid plaque burden are increased in hippocampus and cortex of APP/PSEN1 transgenic mice lacking neuronal LRP6 (Figure 2, panel 2; Liu et al., 2014). LRP6 cKO also exacerbates memory deficits in this AD model (Liu et al., 2014). Together, these findings indicate that LRP6 deficiency-as observed in AD brains-aggravates AD pathology.

How does LRP6 modulate amyloid pathology? LRP6 can directly influence the processing of APP (Figure 2, panel 2). Co-immunoprecipitation assays demonstrated that APP and LRP6 interact via their extracellular domains (Liu et al., 2014). Knockdown of LRP6 in an APP-expressing cell line increases production of $\mathrm{A} \beta$ and its by-products, suggesting that LRP6 downregulation stimulates amyloidogenic processing of APP. In vivo LRP6 deficiency similarly increases endogenous $A \beta_{40}$ and $A \beta_{42}$ levels, whereas overexpression of LRP6 leads to reduced production of $A \beta_{40}$ and $A \beta_{42}$ (Figure 2, panel 2, Liu et al., 2014). LRP6 may modulate $A \beta$ production by promoting cell surface localization of APP (Liu et al., 2014), which favors non-amyloidogenic processing by $\alpha$-secretase (Haass et al., 1993; Parvathy et al., 1999; Carey et al., 2005; Zhang and Song, 2013). These results suggest that LRP6 interacts with APP to retain it at the cell surface, thereby suppressing $A \beta$ production. In contrast, LRP6 deficiency in $\mathrm{AD}$ models increases the amyloidogenic processing of APP, fueling $A \beta$ generation and plaque formation. Therefore, LRP6 loss of function could be part of a positive feedback loop leading to the exacerbation of $\mathrm{AD}$ pathology.

LRP6 may also play a role in other AD-relevant processes, beyond synaptic maintenance and $A \beta$ pathology. First, the influence of non-neuronal glia cells and aberrant immune responses are increasingly recognized as important components of AD pathology (Heneka et al., 2015; Heppner et al., 2015; Zhang and Jiang, 2015; Bronzuoli et al., 2016; De Strooper and Karran, 2016). Genetic, clinical and cell biology data have shown that neuroinflammation driven by microglia and astrocytes plays a significant causal role in driving and exacerbating AD pathogenesis (Heneka et al., 2015; Heppner et al., 2015; Zhang and Jiang, 2015; Bronzuoli et al., 2016). Mutations in several microglia-associated genes are linked to late-onset $\mathrm{AD}$, indicating a central role for microglia in the disease etiology (Jones et al., 2010; Malik et al., 2015; Villegas-Llerena et al., 2016; Efthymiou and Goate, 2017). In addition, microglia may contribute to synapse elimination downstream of A $\beta$ (Paolicelli et al., 2011; Hong et al., 2016a,b). Intriguingly, postnatal neuronal deletion of LRP6 in conditional $\mathrm{KO}$ mice increases the presence of astrocytes and microglia in the aging hippocampus and results in the expression of pro-inflammatory cytokines (Figure 2, panel 3; Liu et al., 2014). These findings suggest that deficiency in neuronal LRP6-mediated Wnt signaling could indirectly promote neuroinflammation during aging, thereby further fueling AD pathogenesis. LRP6 is also expressed in microglia and astrocytes (Halleskog et al., 2011; L'Episcopo et al., 2011; Zhang et al., 2014; Zeisel et al., 2015). However, the role of LRP6 in glia cells in the context of AD remains to be studied. Given that astrocytes have important functions in regulating synaptic transmission and plasticity, they could also contribute to the synaptic defects observed in early stages of $\mathrm{AD}$. Future studies on the impact of LRP6-mediated Wnt signaling on astrocytes could therefore also help to elucidate changes in the astrocyte-neuron crosstalk at synapses in the context of $\mathrm{AD}$.

LRP6 deficiency could further contribute to $\mathrm{AD}$ pathogenesis through its role in lipid metabolism (Figure 2, panel 4). As a member of the extended LDLR receptor family, LRP6 is involved in LDL uptake and cholesterol clearance (Liu et al., 2008; Tomaszewski et al., 2009; Go and Mani, 2012; Ye et al., 2012). Coding-region LRP6 SNP mutations have been associated with elevated LDL cholesterol levels (Mani et al., 2007; Liu et al., 2008; Tomaszewski et al., 2009; Go et al., 2014). Perturbation of lipid metabolism is associated with $\mathrm{AD}$, as gene network analyses have highlighted altered lipid and cholesterol metabolism as one of three biological pathways with a central role in $\mathrm{AD}$ etiology (Jones et al., 2010; Guerreiro et al., 2013; Guerreiro and Hardy, 2014; Hardy et al., 2014; International Genomics of Alzheimer's Disease Consortium (IGAP), 2015; Karch and Goate, 2015; Efthymiou and Goate, 2017). High cholesterol levels in mid-life may contribute to AD susceptibility (Notkola et al., 1998; Kivipelto et al., 2002; Whitmer et al., 2005). The primary function of the major $\mathrm{AD}$ risk gene Apolipoprotein $\mathrm{E}$ $(A P O E)$ is in cholesterol transport (Huang and Mahley, 2014), and ApoE-containing lipoproteins bind to all core members of the LDLR receptor family, to LRP5 and likely to LRP6 as well (Figure 2, panel 4; Kim et al., 1998; Magoori et al., 2003; Beffert et al., 2004; Andersen and Willnow, 2006; Jaeger and Pietrzik, 2008; Guttman et al., 2010). These observations raise the intriguing possibility that LRP6 may also be involved in AD pathogenesis through deregulation of lipid metabolism. Altogether, these findings highlight the importance of LRP6 function and LRP6-mediated Wnt signaling for a healthy aging brain.

\section{CONCLUDING REMARKS}

Long-term synaptic integrity and resilience are vital factors determining the susceptibility to an age-related degenerative disorder such as AD. Indeed, synaptic degeneration is a key early event in the pathophysiology of $\mathrm{AD}$, and exciting new research is shedding more light on important cellular and molecular mechanisms that underpin synaptic vulnerability. 
Wnt signaling and the Wnt co-receptor LRP6 have a central role in synapse formation, stability and function. Growing evidence indicates that deficiency of Wnt signaling contributes to synapse dysfunction and loss in the adult and aging brain, fueling the pathogenesis of $\mathrm{AD}$. Increased levels of the Wnt antagonist Dkk1 or LRP6 loss of function negatively impact on several key pathogenic processes by inducing synapse dysfunction and degeneration as well as deficits in LTP and memory. LRP6 deficiency also promotes $A \beta$ production and amyloid deposition, stimulates neuroinflammation and potentially contributes to aberrant lipid metabolism. These findings point to Dkk1 and LRP6 as important molecular modulators of $\mathrm{AD}$ risk and pathology. Restoring Wnt signaling and LRP6 function may therefore represent a viable therapeutic strategy for AD.

\section{REFERENCES}

Ahmad-Annuar, A., Ciani, L., Simeonidis, I., Herreros, J., Fredj, N. B., Rosso, S. B., et al. (2006). Signaling across the synapse: a role for Wnt and Dishevelled in presynaptic assembly and neurotransmitter release. J. Cell Biol. 174, 127-139. doi: $10.1083 /$ jcb.200511054

Alarcón, M. A., Medina, M. A., Hu, Q., Avila, M. E., Bustos, B. I., PérezPalma, E., et al. (2013). A novel functional low-density lipoprotein receptorrelated protein 6 gene alternative splice variant is associated with Alzheimer's disease. Neurobiol. Aging 34, 1709.e9-1709.e18. doi: 10.1016/j.neurobiolaging. 2012.11.004

Alvarez, A. R., Godoy, J. A., Mullendorff, K., Olivares, G. H., Bronfman, M., and Inestrosa, N. C. (2004). Wnt-3a overcomes $\beta$-amyloid toxicity in rat hippocampal neurons. Exp. Cell Res. 297, 186-196. doi: 10.1016/j.yexcr.2004. 02.028

Alzheimer's Association. (2016). 2016 Alzheimer's disease facts and figures. Alzheimers Dement. 12, 459-509. doi: 10.1016/j.jalz.2016.03.001

Andersen, O. M., and Willnow, T. E. (2006). Lipoprotein receptors in Alzheimer's disease. Trends Neurosci. 29, 687-694. doi: 10.1016/j.tins.2006.09.002

Avila, M. E., Sepúlveda, F. J., Burgos, C. F., Moraga-Cid, G., Parodi, J., Moon, R. T., et al. (2010). Canonical Wnt3a modulates intracellular calcium and enhances excitatory neurotransmission in hippocampal neurons. J. Biol. Chem. 285, 18939-18947. doi: 10.1074/jbc.m110.103028

Bafico, A., Liu, G., Yaniv, A., Gazit, A., and Aaronson, S. A. (2001). Novel mechanism of Wnt signaling inhibition mediated by Dickkopf-1 interaction with LRP6/Arrow. Nat. Cell Biol. 3, 683-686. doi: 10.1038/350 83081

Beaumont, V., Thompson, S. A., Choudhry, F., Nuthall, H., Glantschnig, H., Lipfert, L., et al. (2007). Evidence for an enhancement of excitatory transmission in adult CNS by Wnt signaling pathway modulation. Mol. Cell. Neurosci. 35, 513-524. doi: 10.1016/j.mcn.2007.03.004

Beffert, U., Stolt, P. C., and Herz, J. (2004). Functions of lipoprotein receptors in neurons. J. Lipid Res. 45, 403-409. doi: 10.1194/jlr.r300017-jlr200

Bronzuoli, M. R., Iacomino, A., Steardo, L., and Scuderi, C. (2016). Targeting neuroinflammation in Alzheimer's disease. J. Inflamm. Res. 9, 199-208. doi: $10.2147 /$ jir.s86958

Budnik, V., and Salinas, P. C. (2011). Wnt signaling during synaptic development and plasticity. Curr. Opin. Neurobiol. 21, 151-159. doi: 10.1016/j.conb.2010. 12.002

Carey, R. M., Balcz, B. A., Lopez-Coviella, I., and Slack, B. E. (2005). Inhibition of dynamin-dependent endocytosis increases shedding of the amyloid precursor protein ectodomain and reduces generation of amyloid $\beta$ protein. BMC Cell Biol. 6:30. doi: 10.1186/1471-2121-6-30

Caricasole, A., Copani, A., Caraci, F., Aronica, E., Rozemuller, A. J., Caruso, A., et al. (2004). Induction of Dickkopf-1, a negative modulator of the Wnt pathway, is associated with neuronal degeneration in Alzheimer's brain. J. Neurosci. 24, 6021-6027. doi: 10.1523/jneurosci.1381-04.2004

Cerpa, W., Gambrill, A., Inestrosa, N. C., and Barria, A. (2011). Regulation of NMDA-receptor synaptic transmission by Wnt signaling. J. Neurosci. 31, 9466-9471. doi: 10.1523/jneurosci.6311-10.2011

\section{AUTHOR CONTRIBUTIONS}

JB and PS designed the outline of the article, wrote the manuscript and revised the article. JB created the figures.

\section{FUNDING}

The Wellcome Trust (102267/Z/13/Z), MRC (MR/M024083/1) and Alzheimer's Research UK (ARUK-PG2012-12) supported our work.

\section{ACKNOWLEDGMENTS}

We would like to thank members of our lab for insightful discussions and comments on our manuscript.

Cerpa, W., Godoy, J. A., Alfaro, I., Farías, G. G., Metcalfe, M. J., Fuentealba, R., et al. (2008). Wnt-7a modulates the synaptic vesicle cycle and synaptic transmission in hippocampal neurons. J. Biol. Chem. 283, 5918-5927. doi: 10.1074/jbc.m705943200

Ciani, L., Boyle, K. A., Dickins, E., Sahores, M., Anane, D., Lopes, D. M., et al. (2011). Wnt7a signaling promotes dendritic spine growth and synaptic strength through $\mathrm{Ca}^{2+} /$ Calmodulin-dependent protein kinase II. Proc. Natl. Acad. Sci. U S A 108, 10732-10737. doi: 10.1073/pnas.1018132108

Ciani, L., Marzo, A., Boyle, K., Stamatakou, E., Lopes, D. M., Anane, D., et al. (2015). Wnt signaling tunes neurotransmitter release by directly targeting Synaptotagmin-1. Nat. Commun. 6:8302. doi: 10.1038/ncomms9302

Cissé, M., Halabisky, B., Harris, J., Devidze, N., Dubal, D. B., Sun, B., et al. (2011). Reversing EphB2 depletion rescues cognitive functions in Alzheimer model. Nature 469, 47-52. doi: 10.1038/nature09635

Clevers, H., and Nusse, R. (2012). Wnt/ $\beta$-catenin signaling and disease. Cell 149, 1192-1205. doi: 10.1016/j.cell.2012.05.012

Cong, F., Schweizer, L., Chamorro, M., and Varmus, H. (2003). Requirement for a nuclear function of $\beta$-catenin in Wnt signaling. Mol. Cell. Biol. 23, 8462-8470. doi: $10.1128 / \mathrm{mcb} .23 .23 .8462-8470.2003$

Cruciat, C.-M., and Niehrs, C. (2013). Secreted and transmembrane wnt inhibitors and activators. Cold Spring Harb. Perspect. Biol. 5:a015081. doi: 10.1101/cshperspect.a015081

D'Introno, A., Solfrizzi, V., Colacicco, A. M., Capurso, C., Amodio, M., Todarello, O., et al. (2006). Current knowledge of chromosome 12 susceptibility genes for late-onset Alzheimer's disease. Neurobiol. Aging 27, 1537-1553. doi: 10.1016/j.neurobiolaging.2005.09.020

De Ferrari, G. V., Avila, M. E., Medina, M. A., Perez-Palma, E., Bustos, B. I., and Alarcon, M. A. (2014). Wnt/ $\beta$-catenin signaling in Alzheimer's disease. CNS Neurol. Disord. Drug Targets 13, 745-754. doi: 10.2174/18715273126661312231 13900

De Ferrari, G. V., Chacón, M. A., Barría, M. I., Garrido, J. L., Godoy, J. A., Olivares, G., et al. (2003). Activation of Wnt signaling rescues neurodegeneration and behavioral impairments induced by $\beta$-amyloid fibrils. Mol. Psychiatry 8, 195-208. doi: 10.1038/sj.mp.4001208

De Ferrari, G. V., Papassotiropoulos, A., Biechele, T., Wavrant De-Vrieze, F., Avila, M. E., Major, M. B., et al. (2007). Common genetic variation within the low-density lipoprotein receptor-related protein 6 and late-onset Alzheimer's disease. Proc. Natl. Acad. Sci. U S A 104, 9434-9439. doi: 10.1073/pnas. 0603523104

DeKosky, S. T., and Scheff, S. W. (1990). Synapse loss in frontal cortex biopsies in Alzheimer's disease: correlation with cognitive severity. Ann. Neurol. 27, 457-464. doi: 10.1002/ana.410270502

DeKosky, S. T., Scheff, S. W., and Styren, S. D. (1996). Structural correlates of cognition in dementia: quantification and assessment of synapse change. Neurodegeneration 5, 417-421. doi: 10.1006/neur.1996.0056

De Strooper, B., and Karran, E. (2016). The cellular phase of Alzheimer's disease. Cell 164, 603-615. doi: 10.1016/j.cell.2015.12.056

Dickins, E. M., and Salinas, P. C. (2013). Wnts in action: from synapse formation to synaptic maintenance. Front. Cell. Neurosci. 7:162. doi: 10.3389/fncel.2013. 00162 
Doody, R. S., Raman, R., Farlow, M., Iwatsubo, T., Vellas, B., Joffe, S., et al. (2013). A phase 3 trial of semagacestat for treatment of Alzheimer's disease. N. Engl. J. Med. 369, 341-350. doi: 10.1056/NEJMoa1210951

Doody, R. S., Thomas, R. G., Farlow, M., Iwatsubo, T., Vellas, B., Joffe, S., et al. (2014). Phase 3 trials of solanezumab for mild-to-moderate Alzheimer's disease. N Engl J Med 370, 311-321. doi: 10.1056/NEJMoa1312889

Efthymiou, A. G., and Goate, A. M. (2017). Late onset alzheimer's disease genetics implicates microglial pathways in disease risk. Mol. Neurodegener. 12:43. doi: 10.1186/s13024-017-0184-x

Esparza, T. J., Zhao, H., Cirrito, J. R., Cairns, N. J., Bateman, R. J., Holtzman, D. M., et al. (2013). Amyloid- $\beta$ oligomerization in Alzheimer dementia versus high-pathology controls. Ann. Neurol. 73, 104-119. doi: 10.1002/ana. 23748

Ferreira, S. T., and Klein, W. L. (2011). The A $\beta$ oligomer hypothesis for synapse failure and memory loss in Alzheimer's disease. Neurobiol. Learn. Mem. 96, 529-543. doi: 10.1016/j.nlm.2011.08.003

Forner, S., Baglietto-Vargas, D., Martini, A. C., Trujillo-Estrada, L., and LaFerla, F. M. (2017). Synaptic impairment in alzheimer's disease: a dysregulated symphony. Trends Neurosci. 40, 347-357. doi: 10.1016/j.tins.2017. 04.002

Fortress, A. M., Schram, S. L., Tuscher, J. J., and Frick, K. M. (2013). Canonical Wnt signaling is necessary for object recognition memory consolidation. J. Neurosci. 33, 12619-12626. doi: 10.1523/jneurosci.0659-13.2013

Galli, S., Lopes, D. M., Ammari, R., Kopra, J., Millar, S. E., Gibb, A., et al. (2014). Deficient Wnt signaling triggers striatal synaptic degeneration and impaired motor behaviour in adult mice. Nat. Commun. 5:4992. doi: $10.1038 /$ ncomms5992

García-Velázquez, L., and Arias, C. (2017). The emerging role of Wnt signaling dysregulation in the understanding and modification of ageassociated diseases. Ageing Res. Rev. 37, 135-145. doi: 10.1016/j.arr.2017. 06.001

Go, G. W., and Mani, A. (2012). Low-density lipoprotein receptor (LDLR) family orchestrates cholesterol homeostasis. Yale J. Biol. Med. 85, 19-28.

Go, G. W., Srivastava, R., Hernandez-Ono, A., Gang, G., Smith, S. B., Booth, C. J., et al. (2014). The combined hyperlipidemia caused by impaired Wnt-LRP6 signaling is reversed by Wnt3a rescue. Cell Metab. 19, 209-220. doi: 10.1016/j. cmet.2013.11.023

Gogolla, N., Galimberti, I., Deguchi, Y., and Caroni, P. (2009). Wnt signaling mediates experience-related regulation of synapse numbers and mossy fiber connectivities in the adult hippocampus. Neuron 62, 510-525. doi: 10.1016/j. neuron.2009.04.022

Gordon, M. D., and Nusse, R. (2006). Wnt signaling: multiple pathways, multiple receptors and multiple transcription factors. J. Biol. Chem. 281, 22429-22433. doi: 10.1074/jbc.r600015200

Guerreiro, R., Brás, J., and Hardy, J. (2013). SnapShot: genetics of Alzheimer's disease. Cell 155, 968-968.e1. doi: 10.1016/j.cell.2013.10.037

Guerreiro, R., and Hardy, J. (2014). Genetics of Alzheimer's disease. Neurotherapeutics 11, 732-737. doi: 10.1007/s13311-014-0295-9

Guttman, M., Prieto, J. H., Croy, J. E., and Komives, E. A. (2010). Decoding of lipoprotein-receptor interactions: properties of ligand binding modules governing interactions with apolipoprotein E. Biochemistry 49, 1207-1216. doi: 10.1021/bi9017208

Haass, C., Hung, A. Y., Schlossmacher, M. G., Teplow, D. B., and Selkoe, D. J. (1993). $\beta$-Amyloid peptide and a 3-kDa fragment are derived by distinct cellular mechanisms. J. Biol. Chem. 268, 3021-3024.

Halleskog, C., Mulder, J., Dahlström, J., Mackie, K., Hortobágyi, T., Tanila, H., et al. (2011). WNT signaling in activated microglia is proinflammatory. Glia 59, 119-131. doi: 10.1002/glia.21081

Hardy, J., Bogdanovic, N., Winblad, B., Portelius, E., Andreasen, N., CedazoMinguez, A., et al. (2014). Pathways to Alzheimer's disease. J. Intern. Med. 275, 296-303. doi: 10.1111/joim.12192

He, X., Semenov, M., Tamai, K., and Zeng, X. (2004). LDL receptor-related proteins 5 and 6 in $\mathrm{Wnt} / \beta$-catenin signaling: arrows point the way. Development 131, 1663-1677. doi: 10.1242/dev.01117

Hebert, L. E., Beckett, L. A., Scherr, P. A., and Evans, D. A. (2001). Annual incidence of Alzheimer disease in the United States projected to the years 2000 through 2050. Alzheimer Dis. Assoc. Disord. 15, 169-173. doi: 10.1097/00002093-200110000-00002
Heneka, M. T., Carson, M. J., El Khoury, J., Landreth, G. E., Brosseron, F., Feinstein, D. L., et al. (2015). Neuroinflammation in Alzheimer's disease. Lancet Neurol. 14, 388-405. doi: 10.1016/S1474-4422(15)70016-5

Heppner, F. L., Ransohoff, R. M., and Becher, B. (2015). Immune attack: the role of inflammation in Alzheimer disease. Nat. Rev. Neurosci. 16, 358-372. doi: $10.1038 / \mathrm{nrn} 3880$

Holmes, C., Boche, D., Wilkinson, D., Yadegarfar, G., Hopkins, V., Bayer, A., et al. (2008). Long-term effects of $A \beta 42$ immunisation in Alzheimer's disease: follow-up of a randomised, placebo-controlled phase I trial. Lancet 372, 216-223. doi: 10.1016/S0140-6736(08)61075-2

Hong, S., Beja-Glasser, V. F., Nfonoyim, B. M., Frouin, A., Li, S., Ramakrishnan, S., et al. (2016a). Complement and microglia mediate early synapse loss in Alzheimer mouse models. Science 352, 712-716. doi: 10.1126/science.aad8373

Hong, S., Dissing-Olesen, L., and Stevens, B. (2016b). New insights on the role of microglia in synaptic pruning in health and disease. Curr. Opin. Neurobiol. 36, 128-134. doi: 10.1016/j.conb.2015.12.004

Hsieh, H., Boehm, J., Sato, C., Iwatsubo, T., Tomita, T., Sisodia, S., et al. (2006). AMPAR removal underlies $A \beta$-induced synaptic depression and dendritic spine loss. Neuron 52, 831-843. doi: 10.1016/j.neuron.2006.10.035

Huang, Y., and Mahley, R. W. (2014). Apolipoprotein E: structure and function in lipid metabolism, neurobiology and Alzheimer's diseases. Neurobiol. Dis. 72, 3-12. doi: 10.1016/j.nbd.2014.08.025

Ille, F., and Sommer, L. (2005). Wnt signaling: multiple functions in neural development. Cell. Mol. Life Sci. 62, 1100-1108. doi: 10.1007/s00018-0054552-2

Inestrosa, N. C., and Varela-Nallar, L. (2014). Wnt signaling in the nervous system and in Alzheimer's disease. J. Mol. Cell Biol. 6, 64-74. doi: 10.1002/dvdy.24230

International Genomics of Alzheimer's Disease Consortium (IGAP). (2015). Convergent genetic and expression data implicate immunity in Alzheimer's disease. Alzheimers Dement. 11, 658-671. doi: 10.1016/j.jalz.2014. 05.1757

Jaeger, S., and Pietrzik, C. U. (2008). Functional role of lipoprotein receptors in Alzheimer's disease. Curr. Alzheimer Res. 5, 15-25. doi: 10.2174/ 156720508783884675

Jones, L., Holmans, P. A., Hamshere, M. L., Harold, D., Moskvina, V., Ivanov, D., et al. (2010). Genetic evidence implicates the immune system and cholesterol metabolism in the aetiology of Alzheimer's disease. PLoS One 5:e13950. doi: 10.1371/journal.pone.0013950

Karch, C. M., and Goate, A. M. (2015). Alzheimer's disease risk genes and mechanisms of disease pathogenesis. Biol. Psychiatry 77, 43-51. doi: 10.1016/j. biopsych.2014.05.006

Kawamura, Y., Kikuchi, A., Takada, R., Takada, S., Sudoh, S., Shibamoto, S., et al. (2001). Inhibitory effect of a presenilin 1 mutation on the Wnt signaling pathway by enhancement of $\beta$-catenin phosphorylation. Eur. J. Biochem. 268, 3036-3041. doi: 10.1046/j.1432-1327.2001.02197.x

Kehoe, P., Wavrant-De Vrieze, F., Crook, R., Wu, W. S., Holmans, P., Fenton, I., et al. (1999). A full genome scan for late onset alzheimer's disease. Hum. Mol. Genet. 8, 237-245. doi: 10.1093/hmg/8.2.237

Kim, D.-H., Inagaki, Y., Suzuki, T., Ioka, R. X., Yoshioka, S. Z., Magoori, K., et al. (1998). A new low density lipoprotein receptor related protein, LRP5, is expressed in hepatocytes and adrenal cortex and recognizes apolipoprotein E. J. Biochem. 124, 1072-1076. doi: 10.1093/oxfordjournals.jbchem. a022223

Kivipelto, M., Laakso, M. P., Tuomilehto, J., Nissinen, A., and Soininen, H. (2002). Hypertension and hypercholesterolaemia as risk factors for Alzheimer's disease: potential for pharmacological intervention. CNS Drugs 16, 435-444. doi: 10.2165/00023210-200216070-00001

Knobloch, M., and Mansuy, I. M. (2008). Dendritic spine loss and synaptic alterations in Alzheimer's disease. Mol. Neurobiol. 37, 73-82. doi: 10.1007/s12035-008-8018-z

Koffie, R. M., Meyer-Luehmann, M., Hashimoto, T., Adams, K. W., Mielke, M. L., Garcia-Alloza, M., et al. (2009). Oligomeric amyloid $\beta$ associates with postsynaptic densities and correlates with excitatory synapse loss near senile plaques. Proc. Natl. Acad. Sci. U S A 106, 4012-4017. doi: 10.1073/pnas. 0811698106

L'Episcopo, F., Tirolo, C., Testa, N., Caniglia, S., Morale, M. C., Cossetti, C., et al. (2011). Reactive astrocytes and Wnt/ $\beta$-catenin signaling link nigrostriatal injury to repair in 1-methyl-4-phenyl-1,2,3,6-tetrahydropyridine model of 
Parkinson's disease. Neurobiol. Dis. 41, 508-527. doi: 10.1016/j.nbd.2010. 10.023

Lee, J. H., Cheng, R., Rogaeva, E., Meng, Y., Stern, Y., Santana, V., et al. (2008). Further examination of the candidate genes in chromosome 12p13 locus for late-onset Alzheimer disease. Neurogenetics 9, 127-138. doi: 10.1007/s10048008-0122-8

Libro, R., Bramanti, P., and Mazzon, E. (2016). The role of the Wnt canonical signaling in neurodegenerative diseases. Life Sci. 158, 78-88. doi: 10.1016/j.lfs. 2016.06.024

Liu, W., Mani, S., Davis, N. R., Sarrafzadegan, N., Kavathas, P. B., and Mani, A. (2008). Mutation in EGFP domain of LDL receptor-related protein 6 impairs cellular LDL clearance. Circ. Res. 103, 1280-1288. doi: 10.1161/circresaha.108. 183863

Liu, C.-C., Tsai, C.-W., Deak, F., Rogers, J., Penuliar, M., Sung, Y. M., et al. (2014). Deficiency in LRP6-mediated Wnt signaling contributes to synaptic abnormalities and amyloid pathology in Alzheimer's disease. Neuron 84, 63-77. doi: $10.1016 /$ j.neuron.2014.08.048

MacDonald, B. T., and He, X. (2012). Frizzled and LRP5/6 receptors for Wnt/B-catenin signaling. Cold Spring Harb. Perspect. Biol. 4:a007880. doi: $10.1101 /$ cshperspect.a007880

MacDonald, B. T., Semenov, M. V., Huang, H., and He, X. (2011). Dissecting molecular differences between Wnt coreceptors LRP5 and LRP6. PLoS One 6:e23537. doi: 10.1371/journal.pone.0023537

MacDonald, B. T., Tamai, K., and He, X. (2009). Wnt/ $\beta$-catenin signaling: components, mechanisms, and diseases. Dev. Cell 17, 9-26. doi: 10.1016/j. devcel.2009.06.016

Magoori, K., Kang, M. J., Ito, M. R., Kakuuchi, H., Ioka, R. X., Kamataki, A., et al. (2003). Severe hypercholesterolemia, impaired fat tolerance and advanced atherosclerosis in mice lacking both low density lipoprotein receptorrelated protein 5 and apolipoprotein E. J. Biol. Chem. 278, 11331-11336. doi: $10.1074 / j b c . m 211987200$

Maguschak, K. A., and Ressler, K. J. (2011). Wnt signaling in amygdala-dependent learning and memory. J. Neurosci. 31, 13057-13067. doi: 10.1523/JNEUROSCI. 3248-11.2011

Malik, M., Parikh, I., Vasquez, J. B., Smith, C., Tai, L., Bu, G., et al. (2015). Genetics ignite focus on microglial inflammation in Alzheimer's disease. Mol. Neurodegener. 10:52. doi: 10.1186/s13024-015-0048-1

Mani, A., Radhakrishnan, J., Wang, H., Mani, A., Mani, M. A., NelsonWilliams, C., et al. (2007). LRP6 mutation in a family with early coronary disease and metabolic risk factors. Science 315, 1278-1282. doi: 10.1126/science. 1136370

Mao, B., Wu, W., Li, Y., Hoppe, D., Stannek, P., Glinka, A., et al. (2001). LDLreceptor-related protein 6 is a receptor for Dickkopf proteins. Nature 411, 321-325. doi: $10.1038 / 35077108$

Marzo, A., Galli, S., Lopes, D., McLeod, F., Podpolny, M., Segovia-Roldan, M., et al. (2016). Reversal of synapse degeneration by restoring wnt signaling in the adult hippocampus. Curr. Biol. 26, 2551-2561. doi: 10.1016/j.cub.2016.07.024

Mayeux, R., Lee, J. H., Romas, S. N., Mayo, D., Santana, V., Williamson, J., et al. (2002). Chromosome-12 mapping of late-onset Alzheimer disease among Caribbean Hispanics. Am. J. Hum. Genet. 70, 237-243. doi: 10.1086/324773

McLean, C. A., Cherny, R. A., Fraser, F. W., Fuller, S. J., Smith, M. J., Beyreuther, K., et al. (1999). Soluble pool of A $\beta$ amyloid as a determinant of severity of neurodegeneration in Alzheimer's disease. Ann. Neurol. 46, 860-866. doi: 10.1002/1531-8249(199912)46:6<860::aid-ana8 > 3.0.co;2-m

Miyamoto, T., Kim, D., Knox, J. A., Johnson, E., and Mucke, L. (2016). Increasing the receptor tyrosine kinase EphB2 prevents amyloid- $\beta$-induced depletion of cell surface glutamate receptors by a mechanism that requires the PDZ-binding motif of EphB2 and neuronal activity. J. Biol. Chem. 291, 1719-1734. doi: 10.1074/jbc.M115.666529

Myers, A., Wavrant De-Vrieze, F., Holmans, P., Hamshere, M., Crook, R., Compton, D., et al. (2002). Full genome screen for Alzheimer disease: stage II analysis. Am. J. Med. Genet. 114, 235-244. doi: 10.1002/ajmg.10183

Näslund, J., Haroutunian, V., Mohs, R., Davis, K. L., Davies, P., Greengard, P., et al. (2000). Correlation between elevated levels of amyloid $\beta$-peptide in the brain and cognitive decline. JAMA 283, 1571-1577. doi: 10.1001/jama.283. 12.1571

Niehrs, C. (2006). Function and biological roles of the Dickkopf family of Wnt modulators. Oncogene 25, 7469-7481. doi: 10.1038/sj.onc.1210054
Notkola, I.-L., Sulkava, R., Pekkanen, J., Erkinjuntti, T., Ehnholm, C., Kivinen, P., et al. (1998). Serum total cholesterol, apolipoprotein E $\varepsilon 4$ allele, and Alzheimer's disease. Neuroepidemiology 17, 14-20. doi: 10.1159/000026149

Nusse, R., and Clevers, H. (2017). Wnt/ $\beta$-catenin signaling, disease, and emerging therapeutic modalities. Cell 169, 985-999. doi: 10.1016/j.cell.2017.05.016

Oliva, C. A., Vargas, J. Y., and Inestrosa, N. C. (2013). Wnt signaling: role in LTP, neural networks and memory. Ageing Res. Rev. 12, 786-800. doi: 10.1016/j.arr. 2013.03.006

Palop, J. J., and Mucke, L. (2010). Amyloid- $\beta$-induced neuronal dysfunction in Alzheimer's disease: from synapses toward neural networks. Nat. Neurosci. 13, 812-818. doi: 10.1038/nn.2583

Paolicelli, R. C., Bolasco, G., Pagani, F., Maggi, L., Scianni, M., Panzanelli, P., et al. (2011). Synaptic pruning by microglia is necessary for normal brain development. Science 333, 1456-1458. doi: 10.1126/science.1202529

Park, M., and Shen, K. (2012). WNTs in synapse formation and neuronal circuitry. EMBO J. 31, 2697-2704. doi: 10.1038/emboj.2012.145

Parvathy, S., Hussain, I., Karran, E. H., Turner, A. J., and Hooper, N. M. (1999). Cleavage of Alzheimer's amyloid precursor protein by $\alpha$-secretase occurs at the surface of neuronal cells. Biochemistry 38, 9728-9734. doi: 10.1021/bi9906827

Pei, J.-J., Braak, E., Braak, H., Grundke-Iqbal, I., Iqbal, K., Winblad, B., et al. (1999). Distribution of active glycogen synthase kinase $3 \beta$ (GSK-3 $\beta$ ) in brains staged for Alzheimer disease neurofibrillary changes. J. Neuropathol. Exp. Neurol. 58, 1010-1019. doi: 10.1097/00005072-199909000-00011

Pericak-Vance, M. A., Bass, M. P., Yamaoka, L. H., Gaskell, P. C., Scott, W. K., Terwedow, H. A., et al. (1997). Complete genomic screen in late-onset familial Alzheimer disease. JAMA 278, 1237-1241. doi: 10.1001/jama.278.15.1237

Pickett, E. K., Koffie, R. M., Wegmann, S., Henstridge, C. M., Herrmann, A. G., Colom-Cadena, M., et al. (2016). Non-fibrillar oligomeric amyloid- $\beta$ within synapses. J. Alzheimers Dis. 53, 787-800. doi: 10.3233/JAD-160007

Pinson, K. I., Brennan, J., Monkley, S., Avery, B. J., and Skarnes, W. C. (2000). An LDL-receptor-related protein mediates Wnt signaling in mice. Nature 407, 535-538. doi: 10.1038/35035124

Prince, M., Bryce, R., Albanese, E., Wimo, A., Ribeiro, W., and Ferri, C. P. (2013). The global prevalence of dementia: a systematic review and metaanalysis. Alzheimers Dement. 9, 63.e2-75.e2. doi: 10.1016/j.jalz.2012.11.007

Purro, S. A., Dickins, E. M., and Salinas, P. C. (2012). The secreted Wnt antagonist Dickkopf-1 is required for amyloid $\beta$-mediated synaptic loss. J. Neurosci. 32, 3492-3498. doi: 10.1523/JNEUROSCI.4562-11.2012

Purro, S. A., Galli, S., and Salinas, P. C. (2014). Dysfunction of Wnt signaling and synaptic disassembly in neurodegenerative diseases. J. Mol. Cell Biol. 6, 75-80. doi: $10.1093 / \mathrm{jmcb} / \mathrm{mjt} 049$

Rogaeva, E., Premkumar, S., Song, Y., Sorbi, S., Brindle, N., Paterson, A., et al. (1998). Evidence for an Alzheimer disease susceptibility locus on chromosome 12 and for further locus heterogeneity. JAMA 280, 614-618. doi: 10.1001/jama. 280.7.614

Rosi, M. C., Luccarini, I., Grossi, C., Fiorentini, A., Spillantini, M. G., Prisco, A., et al. (2010). Increased Dickkopf-1 expression in transgenic mouse models of neurodegenerative disease. J. Neurochem. 112, 1539-1551. doi: 10.1111/j.14714159.2009.06566.x

Ross, S. P., Baker, K. E., Fisher, A., Hoff, L., Pak, E. S., and Murashov, A. K. (2018). miRNA-431 prevents amyloid- $\beta$-induced synapse loss in neuronal cell culture model of Alzheimer's disease by silencing kremen1. Front. Cell. Neurosci. 12:87. doi: 10.3389/fncel.2018.00087

Sahores, M., Gibb, A., and Salinas, P. C. (2010). Frizzled-5, a receptor for the synaptic organizer Wnt7a, regulates activity-mediated synaptogenesis. Development 137, 2215-2225. doi: 10.1242/dev.046722

Salinas, P. C. (2012). Wnt signaling in the vertebrate central nervous system: from axon guidance to synaptic function. Cold Spring Harb. Perspect. Biol. 4:a008003. doi: 10.1101/cshperspect.a008003

Salinas, P. C., and Zou, Y. (2008). Wnt signaling in neural circuit assembly. Annu. Rev. Neurosci. 31, 339-358. doi: 10.1146/annurev.neuro.31.060407. 125649

Salloway, S., Sperling, R., Fox, N. C., Blennow, K., Klunk, W., Raskind, M., et al. (2014). Two phase 3 trials of bapineuzumab in mild-to-moderate Alzheimer's disease. N. Engl. J. Med. 370, 322-333. doi: 10.1056/NEJMoa1304839

Schafer, D. P., and Stevens, B. (2010). Synapse elimination during development and disease: immune molecules take centre stage. Biochem. Soc. Trans. 38, 476-481. doi: 10.1042/bst0380476 
Scheff, S. W., Sparks, L., and Price, D. A. (1993). Quantitative assessment of synaptic density in the entorhinal cortex in Alzheimer's disease. Ann. Neurol. 34, 356-361. doi: 10.1002/ana.410340309

Schuijers, J., Mokry, M., Hatzis, P., Cuppen, E., and Clevers, H. (2014). Wntinduced transcriptional activation is exclusively mediated by TCF/LEF. EMBO J. 33, 146-156. doi: 10.1002/embj.201385358

Scott, W. K., Grubber, J. M., Conneally, P. M., Small, G. W., Hulette, C. M., Rosenberg, C. K., et al. (2000). Fine mapping of the chromosome 12 late-onset Alzheimer disease locus: potential genetic and phenotypic heterogeneity. Am. J. Hum. Genet. 66, 922-932. doi: 10.1086/302828

Seib, D. R., Corsini, N. S., Ellwanger, K., Plaas, C., Mateos, A., Pitzer, C., et al. (2013). Loss of Dickkopf-1 restores neurogenesis in old age and counteracts cognitive decline. Cell Stem Cell 12, 204-214. doi: 10.1016/j.stem.2012. 11.010

Selkoe, D. J. (2002). Alzheimer's disease is a synaptic failure. Science 298, 789-791. doi: 10.1126/science.1074069

Sellers, K. J., Elliott, C., Jackson, J., Ghosh, A., Ribe, E., Rojo, A. I., et al. (2018). Amyloid $\beta$ synaptotoxicity is Wnt-PCP dependent and blocked by fasudil. Alzheimers Dement. 14, 306-317. doi: 10.1016/j.jalz.2017.09.008

Semënov, M. V., Tamai, K., Brott, B. K., Kühl, M., Sokol, S., and He, X. (2001). Head inducer Dickkopf-1 is a ligand for Wnt coreceptor LRP6. Curr. Biol. 11, 951-961. doi: 10.1016/S0960-9822(01)00290-1

Shankar, G. M., Li, S., Mehta, T. H., Garcia-Munoz, A., Shepardson, N. E., Smith, I., et al. (2008). Amyloid- $\beta$ protein dimers isolated directly from Alzheimer's brains impair synaptic plasticity and memory. Nat. Med. 14, 837-842. doi: 10.1038/nm1782

Sharma, K., Choi, S. Y., Zhang, Y., Nieland, T. J., Long, S., Li, M., et al. (2013). High-throughput genetic screen for synaptogenic factors: identification of LRP6 as critical for excitatory synapse development. Cell Rep. 5, 1330-1341. doi: 10.1016/j.celrep.2013.11.008

Shimogori, T., VanSant, J., Paik, E., and Grove, E. A. (2004). Members of the Wnt, $\mathrm{Fz}$, and Frp gene families expressed in postnatal mouse cerebral cortex. J. Comp. Neurol. 473, 496-510. doi: 10.1002/cne.20135

Stamatakou, E., and Salinas, P. C. (2014). Postsynaptic assembly: a role for Wnt signaling. Dev. Neurobiol. 74, 818-827. doi: 10.1002/dneu.22138

Stephan, A. H., Barres, B. A., and Stevens, B. (2012). The complement system: an unexpected role in synaptic pruning during development and disease. Annu. Rev. Neurosci. 35, 369-389. doi: 10.1146/annurev-neuro-061010113810

Terry, R. D., Masliah, E., Salmon, D. P., Butters, N., DeTeresa, R., Hill, R., et al. (1991). Physical basis of cognitive alterations in Alzheimer's disease: synapse loss is the major correlate of cognitive impairment. Ann. Neurol. 30, 572-580. doi: 10.1002/ana.410300410

Tomaszewski, M., Charchar, F. J., Barnes, T., Gawron-Kiszka, M., Sedkowska, A., Podolecka, E., et al. (2009). A common variant in low-density lipoprotein receptor-related protein 6 gene (LRP6) is associated with LDL-cholesterol. Arterioscler. Thromb. Vasc. Biol. 29, 1316-1321. doi: 10.1161/atvbaha.109. 185355

Tu, S., Okamoto, S., Lipton, S. A., and Xu, H. (2014). Oligomeric A $\beta$ induced synaptic dysfunction in Alzheimer's disease. Mol. Neurodegener. 9:48. doi: 10.1186/1750-1326-9-48

Valenta, T., Hausmann, G., and Basler, K. (2012). The many faces and functions of $\beta$-catenin. EMBO J. 31, 2714-2736. doi: 10.1038/emboj.2012.150

Varela-Nallar, L., Alfaro, I. E., Serrano, F. G., Parodi, J., and Inestrosa, N. C. (2010). Wingless-type family member $5 \mathrm{~A}$ (Wnt-5a) stimulates synaptic differentiation and function of glutamatergic synapses. Proc. Natl. Acad. Sci. U S A 107, 21164-21169. doi: 10.1073/pnas.1010011107

Vellas, B., Carrillo, M. C., Sampaio, C., Brashear, H. R., Siemers, E., Hampel, H., et al. (2013). Designing drug trials for Alzheimer's disease: what we have learned from the release of the phase III antibody trials: a report from the EU/US/CTAD Task Force. Alzheimers Dement. 9, 438-444. doi: 10.1016/j.jalz. 2013.03.007

Viana da Silva, S., Haberl, M. G., Zhang, P., Bethge, P., Lemos, C., Gonçalves, N., et al. (2016). Early synaptic deficits in the APP/PS1 mouse model of Alzheimer's disease involve neuronal adenosine A2A receptors. Nat. Commun. 7:11915. doi: $10.1038 /$ ncomms11915
Villegas-Llerena, C., Phillips, A., Garcia-Reitboeck, P., Hardy, J., and Pocock, J. M. (2016). Microglial genes regulating neuroinflammation in the progression of Alzheimer's disease. Curr. Opin. Neurobiol. 36, 74-81. doi: 10.1016/j.conb.2015. 10.004

Walsh, D. M., Klyubin, I., Fadeeva, J. V., Cullen, W. K., Anwyl, R., Wolfe, M. S., et al. (2002). Naturally secreted oligomers of amyloid $\beta$ protein potently inhibit hippocampal long-term potentiation in vivo. Nature 416, 535-539. doi: $10.1038 / 416535 a$

Wayman, G. A., Impey, S., Marks, D., Saneyoshi, T., Grant, W. F., Derkach, V., et al. (2006). Activity-dependent dendritic arborization mediated by CaM-kinase I activation and enhanced CREB-dependent transcription of Wnt-2. Neuron 50, 897-909. doi: 10.1016/j.neuron.2006.05.008

Wei, W., Nguyen, L. N., Kessels, H. W., Hagiwara, H., Sisodia, S., and Malinow, R. (2010). Amyloid $\beta$ from axons and dendrites reduces local spine number and plasticity. Nat. Neurosci. 13, 190-196. doi: 10.1038/nn.2476

Whitmer, R. A., Sidney, S., Selby, J., Johnston, S. C., and Yaffe, K. (2005). Midlife cardiovascular risk factors and risk of dementia in late life. Neurology 64, 277-281. doi: 10.1212/01.WNL.0000149519.47454.F2

Xu, N., Zhou, W. J., Wang, Y., Huang, S. H., Li, X., and Chen, Z. Y. (2015). Hippocampal wnt3a is necessary and sufficient for contextual fear memory acquisition and consolidation. Cereb. Cortex 25, 4062-4075. doi: 10.1093/cercor/bhu121

Ye, Z. J., Go, G. W., Singh, R., Liu, W., Keramati, A. R., and Mani, A. (2012). LRP6 protein regulates low density lipoprotein (LDL) receptor-mediated LDL uptake. J. Biol. Chem. 287, 1335-1344. doi: 10.1074/jbc.m111.295287

Zeisel, A., Muñoz-Manchado, A. B., Codeluppi, S., Lönnerberg, P., La Manno, G., Juréus, A., et al. (2015). Brain structure. Cell types in the mouse cortex and hippocampus revealed by single-cell RNA-seq. Science 347, 1138-1142. doi: 10.1126/science.aaa1934

Zenzmaier, C., Marksteiner, J., Kiefer, A., Berger, P., and Humpel, C. (2009). Dkk3 is elevated in CSF and plasma of Alzheimer's disease patients. J. Neurochem. 110, 653-661. doi: 10.1111/j.1471-4159.2009.06158.x

Zhang, Y., Chen, K., Sloan, S. A., Bennett, M. L., Scholze, A. R., O'Keeffe, S., et al. (2014). An RNA-sequencing transcriptome and splicing database of glia, neurons and vascular cells of the cerebral cortex. J. Neurosci. 34, 11929-11947. doi: 10.1523/JNEUROSCI.1860-14.2014

Zhang, Z., Hartmann, H., Do, V. M., Abramowski, D., Sturchler-Pierrat, C., Staufenbiel, M., et al. (1998). Destabilization of $\beta$-catenin by mutations in presenilin-1 potentiates neuronal apoptosis. Nature 395, 698-702. doi: $10.1038 / 27208$

Zhang, F., and Jiang, L. (2015). Neuroinflammation in Alzheimer's disease. Neuropsychiatr. Dis. Treat. 11, 243-256. doi: 10.2147/NDT.S75546

Zhang, X., and Song, W. (2013). The role of APP and BACE1 trafficking in APP processing and amyloid- $\beta$ generation. Alzheimers Res. Ther. 5:46. doi: 10.1186/ alzrt211

Zhou, C.-J., Borello, U., Rubenstein, J. L., and Pleasure, S. J. (2006). Neuronal production and precursor proliferation defects in the neocortex of mice with loss of function in the canonical Wnt signaling pathway. Neuroscience 142, 1119-1131. doi: 10.1016/j.neuroscience.2006.07.007

Zhou, C.-J., Pinson, K. I., and Pleasure, S. J. (2004a). Severe defects in dorsal thalamic development in low-density lipoprotein receptor-related protein-6 mutants. J. Neurosci. 24, 7632-7639. doi: 10.1523/jneurosci.2123-04.2004

Zhou, C.-J., Zhao, C., and Pleasure, S. J. (2004b). Wnt signaling mutants have decreased dentate granule cell production and radial glial scaffolding abnormalities. J. Neurosci. 24, 121-126. doi: 10.1523/jneurosci.4071-03.2004

Conflict of Interest Statement: The authors declare that the research was conducted in the absence of any commercial or financial relationships that could be construed as a potential conflict of interest.

Copyright (C) 2018 Buechler and Salinas. This is an open-access article distributed under the terms of the Creative Commons Attribution License (CC BY). The use, distribution or reproduction in other forums is permitted, provided the original author(s) and the copyright owner(s) are credited and that the original publication in this journal is cited, in accordance with accepted academic practice. No use, distribution or reproduction is permitted which does not comply with these terms. 